\title{
Changes in tactical performance and self- efficacy on young female basketball players
}

\section{Variações na performance tática e na autoeficácia de jovens meninas atletas de basquetebol}

\author{
Thiago José Leonardi \\ (iD) https://orcid.org/0000-0002-3843-2648 \\ Mônica Cristina Starapoli Martins ${ }^{2}$ \\ (D) https://orcid.org/0000-0002-4619-028X \\ Carlos Eduardo de Barros Gonçalves ${ }^{3}$ \\ (D) https://orcid.org/0000-0002-6687-9041 \\ Roberto Rodrigues Paes ${ }^{4}$ \\ (D) https://orcid.org/0000-0002-9333-9294 \\ Humberto Jorge Gonçalves Moreira de Carvalho ${ }^{5}$ \\ (D) https://orcid.org/0000-0002-2855-0296
}

Abstract - The present study examined changes in tactical performance and self-efficacy among young female basketball players across a 4-months competitive season. Repeated measures preand post a 4-month season in 30 young female basketball players (11.4 to 14.7 years-old) was considered. We applied the Self-Efficacy General Scale and examined tactical performance in a standardized 3 vs 3 exercise in half court. The 3 vs 3 exercise was analysed using Game Performance Assessment Instrument (GPAI) and Team Sport Assessment Procedure (TSAP). We examined changes in tactical performance and self-efficacy using multilevel modelling. The results showed that changes of Self-Efficacy scores were not influenced by 4 months of training across competition period, chronological age and years of sport participation, the changes of TSAP performance was influenced only by years of sport participation, and the changes of GPAI performance was influenced only by the period of training and competition games.

Key words: Adolescent; Sports; Statistical analysis.

Resumo - O presente estudo examinou mudanças na performance tática e na autoeficácia de jovens meninas atletas de basquetebol durante quatro meses de treinamento em temporada competitiva. Foram realizadas medidas repetidas pré e pós 4 meses em 30 jovens meninas atletas de basquetebol (11.4 a 14.7 anos). Foi aplicado o questionário Self-Efficacy General Scale e avaliada a performance tática em atividade padronizada $3 \times 3$ utilizando o Game Performance Assessment Instrument (GPAI) e o Team Sport Assessment Procedure (TSAP). Avaliou-se as variaçôes de performance tática e de autoeficácia usando modelação multinivel. Os resultados mostraram que as variações nos scores de autoeficácia não foram influenciados pelos 4 meses de treinamento durante a temporada competitiva, pela idade cronológica e nem pelos anos de participação esportiva; as mudanças de performance no TSAP foram influenciadas apenas pelos anos de participação e as variações de performance no GPAI foram influenciadas apenas pelo periodo de treino e jogos competitivos.

Palavras-chave: Adolescente; Análise estatística; Esporte
1 Federal University of Rio Grande do Sul. School of Physical Education, Physiotherapy and Dance. Porto Alegre, Rio Grande do Sul. Brazil

2 Adventist University Center of São Paulo. Campus Hortolândia. Hortolândia, São Paulo, Brazil

3 University of Coimbra. Faculty of Sport Sciences and Physical Education. Coimbra, Portugal

4 University of Campinas. Faculty of Physical Education. Campinas, São Paulo, Brazil

5 Federal University of Santa Catarina. Department of Physical Education. Florianópolis, Santa Catarina, Brazil

Received: 12 November 2018 Accepted: 25 March 2019

How to cite this article Leonardi TJ, Martins MCS, Gonçalves CEB, Paes RR, Carvalho HJGM. Changes in tactical performance and self-efficacy on young female basketball players. Rev Bras Cineantropom Desempenho Hum 2019, 21:e60180. D0I: http://dx.doi. org/10.1590/1980-0037.2019v21e60180.

Copyright: This work is licensed under a Creative Commons Attribution 4.0 International License. 


\section{INTRODUCTION}

Team sport performance is a complex product of cognitive knowledge about the current situation and past events combined with a player's ability to produce the sport skill(s) required ${ }^{1}$. Hence, knowledge development is relevant on tactical learning and decision making processes and must be implicit on teaching-learning systems ${ }^{2}$. In particularly, basketball performance is highly influenced by body dimensions and functional performance ${ }^{3}$. The complexity of game actions and decisions in basketball may be linked to several psychological constructs.

An important psychological construct in sports is self-efficacy ${ }^{4,5}$. Perceived self-efficacy has been defined as the persons' beliefs in their own capabilities to achieve something ${ }^{6}$. Furthermore, it has been noted a link between sport participation and the development of self-efficacy ${ }^{7,8}$. Hence, in the context of youth sports, particularly basketball, information about perceived self-efficacy may be useful to interpret players' performance and behaviour within the game.

The learning and training of tactical and technical behaviours must be organized by coaches during the training process and the source of the method and the activities to each training content has impact on athletes perceived self-efficacy ${ }^{5,9}$.

Learning and performing tactical and technical behaviours has been of interest to coaches and researchers ${ }^{2,10-12}$. There has been proposals to assess tactical and technical behaviours, particularly applied in the context of Physical Education and youth team sports ${ }^{10-13}$. The Game Performance Assessment Instrument (GPAI) ${ }^{12}$ and the Team Sport Assessment Instrument (TSAP) $)^{13}$ are two popular procedures intended to identify changes in tactical performance applied to children and adolescent players.

Interpreting performance and behaviour of young athletes is not straightforward. Within young athletes substantial age-associated, maturity-associated and sport-specific training experience-associated variation often exists between players ${ }^{14}$. Therefore, caution is warranted with the interpretation of young athletes' performance and development, and appropriate alignment of chronological age, biological age and accumulated sport experience needs to be considered modelled. In the present study we examined the changes in tactical performance, measured both with GPAI and TSAP, and self-efficacy across a 4-month competitive season among female adolescent basketball players using Bayesian multilevel modelling. We also considered the relative contribution of age, training experience and self-efficacy to adolescent female basketball players' variation in tactical scores and respective change across the competitive season. Bayesian methods treat parameters as random variables combining both sample data and prior distribution information to estimate posterior information ${ }^{15,16}$. It offers an intuitive and probabilistic interpretation, conditional on the data, in particular deal with small scale applied team sport studies ${ }^{17}$. Multilevel modelling allows a flexible and robust framework to account for variation 
from different sources and levels of observation, that are not answered with traditional statistical approaches used in sports science ${ }^{18}$.

\section{METHOD}

\section{Participants}

We used pre-post design in this study. Thirty adolescent female basketball players aged between 11.4 to 14.7 years at baseline were considered. Players were engaged in two established youth basketball program which competed at regional competition level supervised by Associação Regional de Basquetebol. Both teams trained about 6 hours per week and the training content was controlled using SIATE ${ }^{19}$. The frequency of tactical and technical activities was similar in both teams (data not shown).

The players were informed about the procedures and nature of the study design, that their participation was voluntary, and they could leave the study at any time. All players and their parents or legal guardians provided written consent. The study was approved by the Research Ethics Committee of the University of Campinas.

\section{Procedures}

Chronological age was calculated to the nearest 0.1 year by subtracting birth date from date of testing. The sample was grouped by two age groups under-13 ( $\mathrm{n}=15)$ and under-15 ( $\mathrm{n}=15)$, which represents the competitive age groups of the players. Years of training were obtained by interview. The coaches of the players (female coaches in all cases) obtained age at menarche with individual interview. Three players had not attained menarche at the date of observation. Data was organized into two groups of menarcheal status: early $(n=19)$, average/late $(n=11)$. Further details for players' classification by menarcheal status are reported elsewhere ${ }^{18}$.

We used the General Self-Efficacy Scale ${ }^{20}$ with 12 items based on a five point Likert-type scale ranging from 1 (not at all and strongly disagree) to 5 (yes definitely and strongly agree). Low scores for initiative and persistence indicate positive self-efficacy factors, and scores for effort indicate positive self-efficacy factor. An overall indicator of self-efficacy was estimated by summing individual scores of effort, and reversed scores of initiative and persistence.

The tactical performances were assessed using a standardized 3 vs 3 exercise, for 10 minutes, in a middle court. The additional adaptation on official basketball rules was the obligation of going out of the 3-points line after recovering the ball possession. The videos were obtained by a video recorder (Sony, Tokyo, Japan). The performance scores were obtained using the TSAP and the GPAI. Given noted limitation of the original GPAI scale we used a more reliable alternative proposa ${ }^{10}$. The reliability of the video observation was established previously for the trained observer (ICC $=0.97$ for TSAP and ICC $=1.00$ for GPAI). 


\section{Statistical analysis}

We used Bayesian multilevel modelling to examine the changes in tactical performance and self-efficacy across a 4-month competitive season among adolescent female basketball players. The hierarchical structure of repeated measures data accounts for observations (level 1) nested within each athlete (level 2). The multilevel model to describe each score response across the 4-months season included the time indicator (dummy variable coded 0 as pre-season and 1 , and 0 as end-season) as population level effects, and allowed to vary as group effects between players. We examine possible aggregation by age group (under 13 vs under 15 ) or by maturity status (early maturers vs average/late maturers) at level 3 on changes in in tactical performance and self-efficacy across a 4-month competitive season. Hence, we explored whether there were substantial group-effects group at level 3, separately for age group or maturity status. No variation substantial variation at level 3 was present in the present for self-efficacy and tactical performance (results not shown).

To examine the relative contribution of age, training experience and self-efficacy to adolescent female basketball players' variation in tactical scores, we used z-scores on all variables included in the model. This procedure is convenient to allow all variables to be interpreted in the same scale. Also standardization was convenient to allow faster computation and convergence attainment of the Markov chains. In this step the predictions were based on varying intercepts models. This decision was based on the Widely Available Information Criterion (WAIC) to compare models ${ }^{15,16}$.

We used "uninformative" priors for all parameters, resulting in estimates that reprise maximum likelihood inferences ${ }^{21}$. When modelling unstandardized we used scores used normal priors $(0,5)$ for population-level and cauchy priors $(0,1)$ for group-level effects. For the models including the standardized variables we used normal priors $(0,1)$ for population-level, and for group-level effects we used cauchy priors $(0,1)$.

We run four chains for 2,000 iterations with a warm-up length of 1,000 iterations. The models were estimated by using Bayesian methods implemented via Markov Chain Monte Carlo (MCMC) simulation and using Hamiltonian Monte Carlo and its extension, the No-U-Turn Sampler using $\operatorname{Stan}^{22}$, obtained using brms package ${ }^{23}$, available as a package in the $\mathrm{R}$ statistical language ${ }^{24}$.

\section{RESULTS}

Descriptive statistics and uncertainty estimates for the total sample and by age group are summarized in Table 1 . Three players had not attained menarche at time of observation.

Bayesian multilevel modelling describing changes in tactical performance and self-efficacy across a 4-months competitive season in female adolescent basketball players are summarized in Table 2. There were no substantial changes in self-efficacy factors, as well the overall score between 
pre- and post-season, although a trend of improvement on effort was apparent. An improvement on tactical performance after the 4-months season was observed with GPAI score. However, no change on tactical performance was apparent when considering TSAP score. No substantial differences between players grouped by age group or maturity status were observed (results not shown).

Table 1. Descriptive statistics at baseline for the total sample and grouped by age group.

\begin{tabular}{|c|c|c|c|}
\hline & All sample $(n=30)$ & U13 $(n=15)$ & U15 $(n=15)$ \\
\hline Chronological age, years & $13.3(13.1$ to 13.6$)$ & 12.6 (12.4 to 12.98 & 14.0 (13.8 to 14.2$)$ \\
\hline Age of menarche, years ${ }^{a}$ & $11.3(11.0$ to 11.7$)$ & 10.7 (10.3 to 11.2$)$ & 11.8 (11.4 to 12.3$)$ \\
\hline Years of sport experience, years & 2.6 (2.2 to 3.0$)$ & $2.6(2.1$ to 3.0$)$ & 2.7 (2.2 to 3.1$)$ \\
\hline TSAP $^{\mathrm{b}}, \#$ & 16.5 (15.1 to 17.9$)$ & $16.4(14.5$ to 18.1$)$ & 16.6 (14.9 to 18.3$)$ \\
\hline $\mathrm{GPAl}^{\circ}, \#$ & $0.54(0.53$ to 0.56$)$ & $0.53(0.52$ to 0.56$)$ & $0.55(0.53$ to 0.58$)$ \\
\hline \multicolumn{4}{|l|}{ Self-efficacy } \\
\hline Initiatived & 1.56 (1.40 to 1.73$)$ & $1.49(1.26$ to 1.7$)$ & 1.63 (1.42 to 1.85$)$ \\
\hline Effort & 4.18 (4.09 to 4.29$)$ & 4.18 (4.01 to 4.30$)$ & 4.19 (4.07 to 4.31$)$ \\
\hline Persistence $^{d}$ & 2.47 (2.29 to 2.64) & 2.54 (2.33 to 2.78) & 2.39 (2.14 to 2.62$)$ \\
\hline Self-efficacy score & $10.2(9.82$ to 10.5$)$ & $10.1(9.8$ to 10.5$)$ & $10.2(9.8$ to 10.6$)$ \\
\hline
\end{tabular}

Note. a based on 27 players as 3 players had not attained menarche. b Team Performance Assessment Instrument. c Game Performance Assessment Instrument. d lower scores indicate higher self-efficacy in these factors.

Table 2. Changes across 4-month for self-efficacy and tactical performance among female adolescent basketball players.

\begin{tabular}{|c|c|c|c|c|c|c|}
\hline & \multicolumn{4}{|c|}{ Self-efficacy } & \multicolumn{2}{|c|}{ Tactical Performance } \\
\hline & Initiative & Effort & Persistence & $\begin{array}{l}\text { Self-efficacy } \\
\text { score }\end{array}$ & $\mathrm{GPAl}^{\mathrm{a}}$ & TSAPb \\
\hline \multicolumn{7}{|c|}{ Population-level effects (95\% credible intervals) } \\
\hline Intercept & 1.49 (1.25 to 1.72$)$ & 4.10 (3.97 to 4.23$)$ & 2.50 (2.25 to 2.75$)$ & 10.1 (9.6 to 10.6) & $0.53(0.51$ to 0.55$)$ & 16.90 (14.84 to 18.96 \\
\hline $\begin{array}{l}\text { Change after } \\
4 \text {-months }\end{array}$ & $0.15(-0.17$ to 0.47$)$ & $0.16(-0.03$ to 0.35$)$ & $-0.06(-0.38$ to 0.26$)$ & $0.1(-0.6$ to 0.8$)$ & $0.02(0.00$ to 0.04$)$ & $-1.60(-4.25$ to 1.00$)$ \\
\hline \multicolumn{7}{|c|}{ Group-level effects ( $95 \%$ credible intervals) } \\
\hline $\begin{array}{l}\text { Level } 1 \text { standard } \\
\text { deviation }\end{array}$ & $0.63(0.51$ to 0.77$)$ & 0.30 (0.16 to 0.42$)$ & $0.62(0.48$ to 0.77$)$ & $1.2(0.9$ to 1.6$)$ & $0.04(0.03$ to 0.05$)$ & 5.00 (3.68 to 6.45$)$ \\
\hline \multicolumn{7}{|l|}{$\begin{array}{l}\text { Level } 2 \text { standard } \\
\text { deviation }\end{array}$} \\
\hline Intercept & $0.16(0.01$ to 0.40$)$ & 0.15 (0.01 to 0.33$)$ & $0.28(0.02$ to 0.55$)$ & $0.5(0.0$ to 1.1$)$ & 0.04 (0.03 to 0.06) & $2.15(0.06$ to 4.79$)$ \\
\hline $\begin{array}{l}\text { Change after } \\
\text { 4-months }\end{array}$ & - & 0.28 (0.02 to 0.52) & - & $0.5(0.0$ to 1.3$)$ & - & - \\
\hline
\end{tabular}

Note. a Team Performance Assessment Instrument. b Game Performance Assessment Instrument.

Estimates of the relative contribution and uncertainty of chronological age, years of formal training and self-efficacy score to changes in tactical performance indicators are given in Table 3. When accounting for differences between players in chronological age, years of formal training experience and self-efficacy training, the magnitude of improvements in GPAI scores after 4-months season exposure were, at least moderate. There was a small to trivial, at best, relative contribution of years of formal training experience to GPAI scores. As for TSAP scores, players with more years 
of training experience had higher scores, but changes after the 4-months competitive season remained unchanged. There was no relation between both GPAI and TSAP scores with self-efficacy score.

Table 3. Changes across 4-month for self-efficacy and tactical performance among female adolescent basketball players.

\begin{tabular}{|c|c|c|}
\hline & \multicolumn{2}{|l|}{ Tactical Performance } \\
\hline & $\mathrm{GPAl}^{\mathrm{a}}$ & TSAPb \\
\hline \multicolumn{3}{|c|}{ Population-level effects (95\% credible intervals) } \\
\hline Intercept & $-0.18(-0.57$ to 0.19$)$ & $0.16(-0.19$ to 0.54$)$ \\
\hline Change after 4-months & $0.36(-0.04$ to 0.73$)$ & $-0.32(-0.76$ to 0.14$)$ \\
\hline Chronological age & $0.08(-0.24$ to 0.41$)$ & $0.08(-0.23$ to 0.37$)$ \\
\hline Years of experience & $0.18(-0.13$ to 0.50$)$ & $0.29(0.00$ to 0.59$)$ \\
\hline Self-efficacy & $0.15(-0.07$ to 0.37$)$ & $0.09(-0.16$ to 0.34$)$ \\
\hline \multicolumn{3}{|c|}{ Group-level effects ( $95 \%$ credible intervals) } \\
\hline Level 1 standard deviation & $0.04(0.03$ to 0.05$)$ & 0.85 (0.66 to 1.10$)$ \\
\hline \multicolumn{3}{|l|}{ Level 2 standard deviation } \\
\hline Intercept & $0.04(0.03$ to 0.06$)$ & $0.46(0.04$ to 0.85$)$ \\
\hline
\end{tabular}

Note. a Team Performance Assessment Instrument. b Game Performance Assessment Instrument.

\section{DISCUSSION}

The present study examined the changes in tactical performance, measured both with GPAI and TSAP, and self-efficacy across a 4-month competitive season among female adolescent basketball players, using Bayesian multilevel modelling. The present study also examined the relative contribution of age, training experience and self-efficacy to adolescent female basketball players' variation in tactical scores and respective change across the competitive season.

The present sample of adolescent female basketball players was, on average, advanced in maturity status expressed by mean age at menarche. The mean age at menarche was 11.3 years, which is somewhat earlier than comparable worldwide and Brazilian observations ${ }^{25,26}$. Three of the 30 players in the sample had not attained menarche at the observation date.

A large variation for self-efficacy scores between players at the baseline was observed (Table 2), independent of age group and menarcheal status (data not shown). Self-efficacy may be related to technical performance and participation in game in basketball ${ }^{9}$. However, our results with adolescent female players do not concur with these observations. Changes in perceived self-efficacy across the 4-months competitive season were homogenous for all players, as variation (i.e., group-level effects, see Table 3) was present at baseline and remained mostly similar after the season. In this interpretation seems reasonable assuming that the players in the present sample had, at least, different levels participation in the games across the season. However, it was not possible to measure game participation accurately across the 4-month season. The promotion of positive training and competitive 
environments may be useful to the development of self-efficacy ${ }^{7,8}$, as scores in the present sample indicate a high level of self-efficacy.

The measures of tactical performance showed contrasting responses. GPAI scores improved after the 4-months competitive season, while the TSAP scores remained similar to baseline, independent of age group or menarcheal status. These contrasts between tactical indicators may reflect their methodological differences. Note that concerns have been raised previously both methods ${ }^{2,10}$, particularly reliability of observations, procedure to derive the score and coding systems.

The use of procedures like TSAP and GPAI has been is linked with game-based approaches. Game-based approaches are supported by constructivist teaching learning point of view (student/athlete-based approach) offering an opportunity to train under new prospects, needed to leading learners improve their integrated knowledge and skills in a more innovative learning context ${ }^{27}$. The procedures to assess tactical performance can inform coaches about the cognitive knowledge and decision making evolution, deciding and adjusting his planning accordingly to the need of the player and teams learning needs ${ }^{2}$. The present data showed that both scores were sensible to accumulated training experience, with more experienced players having higher scores. Future studies using TSAP or GPAI should consider the influence of training experience on players' tactical performance and sensitiveness of the instruments.

\section{CONCLUSION}

In summary, we examined the changes in tactical performance and selfefficacy across a 4-month competitive season among female adolescent basketball players. There was substantial variation between the adolescent female basketball in tactical performance and perceived self-efficacy. However, only effort scale of self-efficacy and GPAI score changed substantially after exposure to a 4-months competitive season. These results highlight the need to consider both biological and environmental factors when interpreting the development of young basketball players.

\section{COMPLIANCE WITH ETHICAL STANDARDS}

\section{Funding}

The study was supported by the grant 2018/06402-7, São Paulo Research Foundation (FAPESP).

\section{Ethical approval}

Ethical approval was obtained from the local Human Research Ethics Committee -State University of Campinas and the protocol (no. 49143515.3.0000.5404) was written in accordance with the standards set by the Declaration of Helsinki. 


\section{Conflict of interest statement}

The authors have no conflict of interests to declare.

\section{Author Contributions}

Conceived and designed the experiments: TJL, CEBG, RRP, HJGMC. Performed the experiments: TJL, MCSM. Analyzed the data: TJL, MCSM, CEBG, RRP, HJGMC. Contributed reagents/materials/analysis tools: TJL, MCSM, CEBG, RRP, HJGMC. Wrote the paper: TJL, MCSM, CEBG, RRP, HJGMC.

\section{REFERENCES}

1. Thomas JR, French KE, Humphries CA. Knowledge Development and Sport Skill Performance: Directions for Motor Behavior Research. J Sport Psychol 1986;8(4):259-272.

2. Catarino LM, Carvalho HM, Gonçalves CE. Analysing tactical knowledge through team sport assessment procedure/TSAP: a case study in basketball. Sport TK: Rev Euroam Cienc Dep 2017;6 (Supl.):141-146.

3. Drinkwater EJ, Pyne DB, McKenna MJ. Design and interpretation of anthropometric and fitness testing of basketball players. Sports Med 2008;38(7):565-578.

4. Feltz DL. Self-confidence and sports performance. Stud 2007;33(41):50-66.

5. Lázaro I, Villamarín F. Capacidad predictiva de la auto-eficacia individual y colectiva sobre el rendimiento en jugadoras de baloncesto. J Sport Psychol 1993;2(2):i-ii.

6. Bandura A. On the functional properties of perceived self-efficacy revisited. Los Angeles: Sage Publications; 2012.

7. Beenackers MA, Kamphuis CB, Burdorf A, Mackenbach JP, van Lenthe FJ. Sports participation, perceived neighborhood safety, and individual cognitions: how do they interact? Int J Behav Nutr Phys Act 2011;8(1):76.

8. Graham DJ, Schneider M, Dickerson SS. Environmental resources moderate the relationship between social support and school sports participation among adolescents: a cross-sectional analysis. Int J Behav Nutr Phys Act 2011;8(1):34.

9. Ortega E, Olmedilla A, de Baranda PS, Gómez MÁ. Relationship between the level of self-efficacy, performance indicators, and participation in youth basketball. J Sport Psychol 2009;18(3):337-342.

10. Memmert D, Harvey S. The game performance assessment instrument (GPAI): some concerns and solutions for further development. J Teach Phys Educ 2008;27(2):220-240.

11. Nadeau L, Godbout P, Richard J-F. Assessment of ice hockey performance in real-game conditions. Eur J Sport Sci 2008;8(6):379-388.

12. Oslin J, Mitchell S, Griffin L. The Game Performance Assessment Instrument (GPAI): Development and preliminary validation. J Teach Phys Educ 1998;17(2):231-243.

13. Gréhaigne J-F, Godbout P, Bouthier D. Performance Assessment in Team Sports. J Teach Phys Educ 1997; 16(4), 500-516.

14. Carvalho HM, Goncalves CE, Collins D, Paes RR. Growth, functional capacities and motivation for achievement and competitiveness in youth basketball: an interdisciplinary approach. J Sports Sci. 2018;36(7):742-748.

15. Gelman A, Carlin JB, Stern HS, Dunson DB, Vehtari A, Rubin DB. Bayesian Data Analysis, Third Edition. Boca Raton: Chapman \& Hall/CRC Press; 2013.

16. McElreath R. Statistical rethinking: a Bayesian course with examples in $\mathrm{R}$ and Stan. Boca Raton: Chapman \& Hall/CRC Press; 2015.

17. Carvalho HM, Gonçalves CE, Grosgeorge B, Paes RR. Validity and usefulness of the Line Drill test for adolescent basketball players: a Bayesian multilevel analysis. Res Sports Med 2017; 25(3): 333-344. 
18. Leonardi TJ, Paes RR, Breder L, Foster C, Gonçalves CE, Carvalho HM. Biological maturation, training experience, body size and functional capacity of adolescent female basketball players: A Bayesian analysis. Int J Sports Sci Coach 2018; 13(5):713-722.

19. Ibáñez SJ, Feu S, Cañadas M. Sistema integral para el análisis de las tareas de entrenamiento, SIATE, en deportes de invasión. Rev Cienc Deporte 2016;12(1):3-30.

20. Bosscher RJ, Smit JH. Confirmatory factor analysis of the general self-efficacy scale. Behav Res Ther 1998;36(3):339-343.

21. McElreath R, Koster J. Using multilevel models to estimate variation in foraging returns. Effects of failure rate, harvest size, age, and individual heterogeneity. Hum Nat 2014;25(1):100-120.

22. Stan Development Team. Stan: A C++ Library for Probability and Sampling. 2015; Available from: http://mc-stan.org/ [2019 jun 3].

23. Bürkner P-C. brms: An R Package for Bayesian Multilevel Models using Stan. J Stat Softw 2017;80(1):1-28.

24. R Core Team. R: A Language and Environment for Statistical Computing. Vienna, Austria: R Foundation for Statistical Computing. 2015; Available from: http:// www.R-project.org/ [2019 jun 3].

25. Duarte MFS. Physical maturation: a review with special reference to Brazilian children. Cad Saúde Pública 1993;9: S71-S84.

26. Eveleth B, P., Tanner JM. Worldwide Variation in Human Growth. Cambridge: Cambridge University Press; 1991.

27. Serra-Olivares J, Gonzalez-Villora S, Garcia-Lopez L, Araujo D. Game-Based Approaches' Pedagogical Principles: Exploring Task Constraints in Youth Soccer. J Hum Kinet 2015;46(1):251-261.

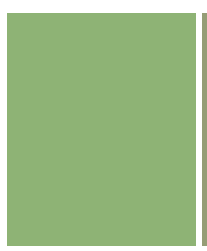

Corresponding author

Thiago José Leonardi

School of Physical Education, Physiotherapy and Dance

Federal University of Rio Grande do Sul

750 Felizardo Street, Porto Alegre, RS

90690-200, Brazil

E-mail: thiago.leonardi@ufrgs.br 